\title{
JERARQUÍA CONSTITUCIONAL Y APLICACIÓN PREFERENTE DEL DERECHO DE LA INTEGRACIÓN. ELEMENTOS PARA LA SOLUCIÓN DEL POSIBLE CONFLICTO ENTRE DERECHOS E INTEGRACIÓN*
}

\author{
CONSTITUTIONAL HIERARCHY AND \\ PREFERENTIAL APPLICATION. THE \\ POTENTIAL CONFLICT BETWEEN RIGHTS \\ AND INTEGRATION IN THE INTEGRATION LAW
}

\author{
Eric Tremolada Álvarez*** \\ Rubén Martínez Dalmau*** \\ Fecha de recepción: 15 de agosto de 2013 \\ Fecha de aceptación: 20 de octubre de 2013 \\ Disponible en linea: 30 de junio de 2013
}

\section{Para citar este artículo / To cite this article}

Eric Tremolada Álvarez \& Rubén Martínez Dalmau, Jerarquía constitucional y aplicación preferente del derecho de la integración. Elementos para la solución del posible conflicto entre derechos e integración, 128 Vniversitas (2014). http://dx.doi.org/10.11144/Javeriana.VJ128.jcap

doi:10.11144/Javeriana.VJ128.jcap

* Reflexión y análisis que se enmarca dentro del proyecto de investigación sobre las compatibilidades de las obligaciones económicas, que se realiza al interior de la línea de integración y comercio del Grupo de Investigación en Integración y Comercio de la Universidad Externado de Colombia.

** Abogado dedicado a la docencia e investigación del derecho internacional público y al derecho de la integración, titular en Colombia de la Cátedra Jean Monnet de Derecho de la Integración Comparado: Unión Europea-América Latina, que se imparte en Universidad Externado con el aval de la Comisión Europea. Doctor en derecho de la Universitat de València, España, tras haber obtenido un dea en Derecho Internacional y Relaciones Internacionales por la Universidad Complutense de Madrid e Instituto Universitario Ortega y Gasset; un máster en Análisis y Gestión de Ciencia y Tecnología en la Universidad Carlos III; una especialización en Derecho Constitucional y Ciencia Política del Centro de Estudios Constitucionales de Madrid, y un diploma en Altos Estudios Internacionales de la Sociedad de Estudios Internacionales de España. Autor y editor de diversos libros, artículos y ensayos, y colaborador de medios escritos. Correo electrónico: eric. tremolada@uexternado.edu.co

*** Profesor Titular de derecho Constitucional de la Universitat de València, España. Doctor en derecho y Licenciado en derecho por la Universitat de València. Diploma de Estudios Avanzados y Licenciado en Ciencias Políticas por la Universidad Nacional de Educación a Distancia. Diplomado en ordenamiento Jurídico Comunitario por la Universitat de València. Fue investigador del Polo Europeo Jean Monnet, e imparte docencia en derecho constitucional, derecho de la Unión Europea e Instituciones europeas en varias universidades europeas y latinoamericanas. Correo electrónico: ruben.martinez@uv.es 


\section{RESUMEN}

La relación conflictiva entre integración y Constitución nace tempranamente con el surgimiento de las Comunidades europeas a causa del conflicto entre la dinámica de la integración, fundada en un límite a la soberanía de los Estados, y la constitucional, destinada a la regulación organizativa y la determinación de los derechos. Las cláusulas constitucionales de apertura ofrecían el marco para la cesión de competencias en los procesos de integración sin que se entendiera que se trataba de un cheque en blanco en favor de instituciones supranacionales.

La solución de la tensión se resuelve con la distinción entre jerarquía y aplicación, la reducción de los ámbitos supranacionales a las competencias explícitamente cedidas en el marco constitucional, y el mantenimiento de la Constitución como norma de normas. De esta manera el derecho comunitario puede gozar de primacía sobre la Constitución en cuanto a su aplicación, pero la legitimidad del derecho comunitario, en última instancia, reside en la propia Constitución. Se soluciona así el posible conflicto entre derechos constitucionalmente protegidos e integración.

Palabras clave: jerarquía; aplicación; integración; primacía; derechos; Constitución democrática 


\section{ABSTRACT}

The troubled relation between integration and Constitution comes early with the emergence of the European Communities as a result of the integration dynamic, based on a limit to the states sovereignty, and the constitutional dynamic, aimed to the organizational control and the determination of the rights. The opening constitutional clauses provided the framework for the cession of competences within integration processes without being understood that it was a blank check in favor of supranational institutions.

The solution to the tension is resolved with the distinction between hierarchy and implementation, the reduction of the supranational sphere to the competences explicitly assigned within the constitutional framework, and the maintenance of the Constitution as supreme law. Thus the Community Law may have precedence over the Constitution in its application, but the legitimacy of the Community Law, ultimately resides in the Constitution itself. That corrects the potential conflict between constitutionally protected right sand integration.

Keywords: hierarchy; implementation; integration; precedence; rights; democratic Constitution

\section{SUMARIO}

INTRODUCCIÓN.- I. INTEGRACIÓN Y CONSTITUCIÓN: UNA RELACIÓN CONFLICTIVA EN EL MARCO DEMOCRÁTICO.- II. CONSECUENCIAS DE LA RELACIÓN ENTRE JERARQUÍA Y APLICACIÓN: PRIMACÍA DEL DERECHO DE LA INTEGRACIÓN Y SUPREMACÍA DE LA CONSTITUCIÓN DEMOCRÁTICA.- III. PRIMACÍA Y SUPREMACÍA EN EL NUEVO CONSTITUCIONALISMO LATINOAMERICANO: LOS CASOS DE COLOMBIA (1991), VENEZUELA (1999), ECUADOR (2008) Y BOLIVIA (2009).- CONCLUSIONES. 


\section{INTRODUCCIÓN}

La relación entre el derecho constitucional y el derecho internacional ha sido, desde sus inicios, tensa al menos en dos aspectos. Por un lado, la naturaleza supraestatal del derecho internacional, que es su razón de ser y que en ocasiones encaja con dificultades en la capacidad organizadora y determinadora de derechos de la Constitución y la regulación de los procesos de validación del derecho y, en varios casos, la determinación de las mismas fuentes del derecho y su jerarquía normativa; por otro lado, un elemento primordial en cuanto a la legitimidad: la Constitución democrática es expresión directa de la voluntad constituyente y, por lo tanto, legitimadora del resto del ordenamiento constituido; el derecho internacional, como el resto del ordenamiento jurídico, obtiene su legitimidad de la Constitución. Son dos distinciones clave para entender los detalles de una relación de por sí compleja, que lo es aún más en el ámbito de las relaciones de integración, como los acuerdos comerciales.

Ahora bien, el carácter supraestatal del derecho internacional establece importantes elementos a tener en cuenta en el análisis de su relación con la Constitución: en primer lugar, cabe tener presente que es el compromiso de sujetos internacionales, principalmente los Estados, el que constituye la voluntad fundadora del derecho internacional, por lo que este cuenta con procedimientos propios de creación, modificación y extinción, aparte de los habituales en el resto del ordenamiento jurídico interno. La existencia del derecho internacional depende necesariamente del compromiso entre la diversidad de sujetos regidos por diferentes ordenamientos jurídicos y sin un nexo constitucional en común. En segundo lugar, esta situación es aún más compleja en ese tertium genus conocido generalmente como derecho de la integración, por cuanto directa o indirectamente se produce una transferencia competencial desde el plano interno al internacional y, por lo tanto, puede resentirse la capacidad competencial constitucional en el caso de que la Constitución regule la competencia transferida.

En efecto, en el caso del derecho internacional general, la primacía de este sobre la Constitución es solo una posibilidad, más bien poco habitual, presente en las propias Constituciones, y tiene lugar principalmente respecto a la vigencia de los tratados internacio- 
nales que establezcan normas más favorables para los ciudadanos; no es, por lo tanto, un problema práctico, aunque sí puede serlo en el nivel teórico. Pero la primacía del derecho de la integración sobre todo el derecho interno, incluida en su caso la Constitución, es una característica necesaria para su existencia, pues en ningún otro caso podría hablarse realmente de transferencia competencial. Ahora bien; este requerimiento, que está en la base de la propia existencia del ordenamiento jurídico comunitario, puede suscitar problemas no solo de legitimidad, sino de desprotección de los derechos configurados constitucionalmente. De ahí la necesidad de establecer anclajes constitucionales suficientes que legitimen la transferencia competencial en los procesos de integración, sin los cuales no existiría la capacidad de integrarse sin afectar al sistema competencial constitucional y, por lo tanto, se perdería cualquier legitimidad para ello; también es necesario determinar los detalles, llegado el caso, de la relación entre derecho de la integración y derechos constitucionales.

El presente trabajo busca ahondar en la distinción entre máxima jerarquía constitucional (supremacía de la Constitución) y aplicación preferente del derecho de la integración (primacía del derecho de la integración) para avanzar soluciones en la relación entre derecho de la integración y Constitución, en particular lo que incide sobre los derechos de configuración constitucional. El análisis de ambos conceptos es básico en el marco de la relación de validez entre derecho internacional — en particular, el de la integración- y Constitución. Cabe solucionar la aparente contradicción sobre cómo sería posible que un ordenamiento jurídico dependa en su validez de una Constitución y, a su vez, goce de primacía sobre ella; solo a través de esta primacía pueden verse realizados mandatos constitucionales como la transferencia de competencias o la plena vigencia de los tratados internacionales, que instituyan derechos más favorables que los configurados constitucionalmente. Pero esta aplicación preferente no puede desmejorar la protección constitucional de los derechos porque, en ese caso, la Constitución perdería su carácter de norma suprema. 


\section{INTEGRACIÓN Y CONSTITUCIÓN: UNA RELACIÓN CONFLICTIVA EN EL MARCO DEMOCRÁTICO}

El derecho internacional no es un fenómeno reciente, sino que surge con la conformación del Estado moderno como forma política de origen del poder; pero su reconocimiento constitucional es más cercano. Como ha puesto de relieve Fix-Zamudio 1 , a partir de la Constitución de Weimar se inicia el reconocimiento constitucional del derecho internacional como parte integrante del derecho interno, situación que progresará notablemente en la segunda posguerra en tres sentidos: el reconocimiento amplio de la primacía del derecho internacional general, la creación del llamado derecho comunitario - $\mathrm{O}$, como ha sido denominado posteriormente, derecho de la integración-, y respecto al derecho internacional de los derechos humanos. El derecho comunitario se configuró de manera diferenciada al derecho internacional general a partir de la creación de las primeras Comunidades europeas (Comunidad Europea del Carbón y del Acero, Tratado de París, 1951; Comunidad Europea de la Energía Atómica y Comunidad Económica Europea, Tratados de Roma, 1957).

La profundización de un derecho comunitario, cuyo objetivo era la integración de determinadas competencias en un ámbito supranacional, creó rápidamente conflictos importantes en el seno de la validez de los ordenamientos jurídicos. A diferencia del derecho internacional general, el derecho de la integración dejaba en manos de instituciones comunitarias la gestión completa de competencias anteriormente nacionales que eran, por lo tanto, responsabilidad de las constituciones de los Estados miembros. Desde muy temprano, el máximo responsable de la aplicación del nuevo derecho, el Tribunal de Justicia de las Comunidades Europeas, estableció a partir de 1963 (sentencia Gend and Loos) una sólida línea jurisprudencial en la que diferenciaba el derecho comunitario como un ordenamiento jurídico propio, independiente de los Estados, que estos debían cumplir; solo así podría realmente producirse

1 Héctor Fix-Zamudio, El derecho internacional de los derechos humanos en las Constituciones latinoamericanas y en la Corte Interamericana de Derechos Humanos, Revista Latinoamericana de derecho, No. 1, 141-180, 144-146 (2004). 
legislación supranacional en el contexto firmado en los tratados. La existencia de este ordenamiento jurídico autónomo, creado por instituciones comunitarias, requería de la aplicación del principio de primacía del derecho de la integración. En la sentencia Costa vs ENEL, de 1964, la Corte de Luxemburgo afirmó:

A diferencia de los tratados internacionales ordinarios, el Tratado de la Comunidad Económica Europea creó un ordenamiento jurídico propio integrado en el sistema jurídico de los Estados miembros desde la entrada en vigor del tratado y que vincula a sus órganos jurisdiccionales. Al instituir una comunidad de duración ilimitada, dotada de instituciones propias, de personalidad, de capacidad jurídica, de capacidad de representación internacional, y más en particular de poderes reales derivados de una limitación de competencia o de una transferencia de atribuciones de los Estados a la Comunidad, estos han limitado su soberanía y han creado así un cuerpo normativo aplicable a sus nacionales y a sí mismos.

Se reconocía oficialmente la primacía del derecho comunitario sobre el derecho interno, si bien basada en la complementación con el principio de competencia ${ }^{2}$.

Las condiciones del conflicto estaban dadas. Por un lado, la dinámica constitucional estaba destinada a la regulación de la organización interna y a la protección de los derechos de las personas. Pero el derecho comunitario se fundamentaba en un "límite a la soberanía" de los Estados que afectaba de frente al objetivo y capacidades constitucionales. La Constitución, además, es la expresión del poder constituyente, por lo que crea una organización democrática en la medida en que ella es democrática. El derecho comunitario, por su parte, huía de los estándares de legitimidad de la Constitución, y se producía a través de instituciones, al menos en su origen, más parecidas a las conferencias internacionales que a los parlamentos nacionales. ¿Cómo se circunscribía la legitimidad del derecho comunitario en el marco democrático de la Constitución?

Una primera reacción constitucional fue la incorporación de las denominadas cláusulas de apertura. Con ellas, las Constituciones daban paso a la posibilidad de ceder competencias en los procesos de integración, por lo que se posibilitaba el recorte en la soberanía

2 Miguel Ángel Alegre Martínez, La primacía del derecho comunitario sobre el ordenamiento jurídico estatal: aspectos constitucionales, Revista de Derecho Político No. 38, 43-174, 101 (1993). 
de los Estados al que se refería el Tribunal de Justicia comunitario. Pero las cláusulas de apertura no podían ser un cheque en blanco a favor de las instituciones supranacionales, porque corría el riesgo de una desconstitucionalización material, particularmente grave en cuanto a la determinación y protección de los derechos. De ahí la necesidad de incorporar límites en la aplicación de las cláusulas de apertura, fundamentalmente dos: la reducción de los ámbitos supranacionales a las competencias explícitamente cedidas - contraria a la vis expansiva del principio federal-, y el mantenimiento de la Constitución como norma de normas, esto es, el derecho comunitario podría gozar de primacía sobre la Constitución en cuanto a su aplicación, pero la legitimidad del derecho comunitario, en última instancia, residía en la propia Constitución, a través de las cláusulas de apertura, y solo en segunda instancia en los tratados constitutivos. Por lo tanto, la Constitución seguía cumpliendo su función de garantía de los derechos configurados por ella por cuanto la primacía del derecho comunitario se limitaba a los ámbitos competenciales explícitos, y la existencia del derecho comunitario provenía de la propia Constitución, puesto que esta facilitaba su presencia a través de las cláusulas de apertura; esto es, el derecho de la integración podría aplicarse con preferencia al derecho interno, incluso - en el ámbito competencial concreto - a la propia Constitución, pero la Constitución seguía siendo la norma jerárquica suprema que posibilitaba la primacía del derecho comunitario.

Quedaba, por lo tanto, despejado el camino para solucionar la controversia, y se basaba en la diferencia de funciones y de orígenes entre la supremacía (jerarquía) y la primacía (aplicación). Cabe destacar, no obstante, que esta distinción entre jerarquía y aplicación, a pesar de ser clásica en la teoría del derecho, no ha sido aprovechada en todo su potencial para la solución de conflictos normativos. De hecho, buena parte de la doctrina y de la jurisprudencia ha utilizado solo el criterio jerárquico como mecanismo para resolver las controversias en la aplicación ${ }^{3}$, en vez de tener en cuenta que jerarquía y aplicación hacen referencia a dos cuestiones diferentes: la primera, a una prelación donde existe un orden respecto al origen de la norma, y la segunda al destino del mandato jurídico en

3 V. gr. Miriam Lorena Henríquez Viñas, Jerarquía de los tratados de derechos humanos: análisis jurisprudencial desde el método de casos, 6 Estudios constitucionales No. 2, 73-119 (2008). 
el terreno factual. El hecho de que unas normas prevalezcan sobre otras en el ámbito jerárquico no excluye, como es sabido, que otras normas se apliquen con preferencia a la jerárquicamente superior cuando la propia norma superior lo prevea.

La primacía es un principio fundamental de los ordenamientos jurídicos de la Unión Europea, el Sistema de Integración Centroamericano y la Comunidad Andina. Pese a ello, en los diferentes sistemas jurídicos de los países que componen estos procesos de integración, no se pone de manifiesto una uniformidad para solucionar los conflictos entre norma comunitaria y norma nacional. A diferencia de lo que suele ocurrir en las constituciones federales, los tratados constitutivos de los procesos de integración no suelen contener cláusulas expresas sobre primacía, exponiendo a las normas de los procesos de integración a la atribución del rango que dentro de su ordenamiento jurídico le den los Estados miembros ${ }^{4}$. Si no hubiese mediado el Tribunal de Justicia de las Comunidades Europeas en el citado asunto Costa vs ENEL, de 1964, la Ley Italiana de Nacionalización de la Electricidad de 1962, posterior y contradictoria al tratado de la Comunidad Económica Europea, hubiese primado de acuerdo a la atribución que le dio el Tribunal Constitucional italiano a este último como ley ordinaria, esto es beneficiando a la norma más reciente: "[...] la fuerza vinculante del derecho comunitario no puede en efecto variar de un Estado a otro, en razón de legislaciones internas ulteriores sin que se ponga en peligro la realización de los objetivos del tratado [...]".

Si bien la autonomía del ordenamiento comunitario surgió en virtud de las atribuciones de competencias a favor de las instituciones de integración, esto no quiere decir que se prescinda de la colaboración o complementariedad funcional de los ordenamientos nacionales, toda vez que el primero "está integrado en el sistema jurídico de los Estados miembros" y los dos órdenes se integran para formar parte del derecho que se aplica en cada país. Por su parte, el surgimiento de normas posteriores o la aplicación de normas anteriores incompatibles violarían el principio general de pacta sunt servanda, rector del derecho internacional, por el cual los Estados expresamente se han comprometido a cumplir las obligaciones

4 Cfr. Guy Isaac, Manual de derecho comunitario general, Ariel, Barcelona, 256-257 (2000). 
derivadas tanto de los tratados constitutivos como de los actos expedidos por las instituciones de integración ${ }^{5}$.

Además del caso del derecho de la integración, es en particular otro ámbito donde ha tenido lugar un conflicto de rasgos semejantes: la aplicación de los tratados internacionales de derechos humanos con preferencia al ordenamiento interno, incluida la propia Constitución. Ante Constituciones "débiles", estos tratados significaban la pervivencia de ámbitos de protección de derechos humanos que el ordenamiento interno era incapaz de procurar. De ahí la importancia de encontrar salidas jurídicas y respuestas institucionales internacionales allí donde no existían ni salidas jurídicas ni respuestas institucionales internas ${ }^{6}$. La situación cambió de manera importante ante la redemocratización que significaron las Constituciones "fuertes", fundadas en momentos de ruptura con el pasado y avances hacia una democracia de mayor calidad a través de procesos constituyentes democráticos. En el caso colombiano, por ejemplo, es muy conocida la incorporación de un significado particular del concepto "bloque de constitucionalidad", extendido a otros ámbitos regionales, y que está fundamentado en la armonización del principio de supremacía de la Constitución como norma de normas y la prevalencia de los tratados ratificados por Colombia, que reconocen los derechos humanos y prohíben su limitación en los estados de excepción (Sentencia de la Corte Constitucional C-225/95).

5 Araceli Mangas Martín \& Diego Liñán Nogueras, Instituciones y derecho de la Unión Europea, Tecnos, Madrid, 424 (2006).

6 Como en el caso chileno, respecto al cual Nogueira $(2003,426)$ afirma que "La supremacía de la Constitución no se limita fronteras adentro, estableciendo un dique de contención y desconfianza del derecho internacional de los derechos humanos, debiendo recepcionarlo sin reduccionismos ni paradigmas conceptuales esclerosados que corresponden a concepciones dogmáticas decimonónicas, desconociendo los valores, principios, objeto y fin del sistema de derechos y el contexto de las reformas concretadas en 1989. Es necesario asumir de buena fe que el sistema interno de derechos se refuerza y fortalece con la fuente internacional, tal fue el objeto de la reforma [...] en 1989, con el objeto de aggiornar el empobrecido catálogo de derechos contenido en el texto original de 1980". Humberto Nogueira Alcalá, Los derechos esenciales o humanos contenidos en los tratados internacionales y su ubicación en el ordenamiento jurídico nacional: doctrina y jurisprudencia, 9 Ius et Praxis, No. 1, 403-466, 426 (2003). 


\section{CONSECUENCIAS DE LA RELACIÓN ENTRE JERARQUÍA Y APLICACIÓN: PRIMACÍA DEL DERECHO DE LA INTEGRACIÓN Y SUPREMACÍA DE LA CONSTITUCIÓN DEMOCRÁTICA}

Como consecuencia del razonamiento anterior, la Constitución sigue siendo norma de normas y, por lo tanto, el derecho comunitario aplicado con primacía - por voluntad de la Constituciónsobre el derecho interno no supone una ruptura con el principio de legitimidad democrática, siempre y cuando se realice en el marco competencial correspondiente y no desmejore la configuración constitucional de derechos y su protección. Algo similar ocurre en cuanto a los tratados internacionales de derechos humanos: pueden (y, en los casos en que existe mandato constitucional en este sentido, deben) aplicarse con preferencia a los derechos previstos en la Constitución, siempre y cuando supongan una mejoría en la situación de los derechos de los ciudadanos. En ambos casos estamos ante una aplicación preferente al orden interno, incluida la Constitución, pero determinada por la propia Constitución.

El fundamento para la compatibilidad de la supremacía de la Constitución y la primacía del derecho comunitario se encuentra en la distinción entre jerarquía constitucional y aplicación preferente del derecho de la integración o, en términos de Guastini ${ }^{7}$, entre “jerarquía estructural o formal y jerarquía material". La jerarquía estructural es aquella que se da entre las normas producidas por dos poderes normativos distintos cuando uno de los poderes en cuestión debe su fuente de legitimidad al otro, mientras que la jerarquía material es aquella que tiene lugar entre dos normas cuando una de ellas es inválida en caso de que entre en conflicto con la otra. En general, toda jerarquía material refleja una jerarquía formal, pero no toda jerarquía formal se resuelve en una jerarquía material. El derecho de la integración, o determinados tratados de derechos humanos, pueden ser materialmente jerárquicos a la Constitución (se aplican con preferencia a esta) en los casos en que la propia Constitución lo disponga, pero estructuralmente la Constitución

7 Riccardo Guastini, Normas supremas, Doxa. Cuadernos de Filosofía del derecho, No. 17-18, 257-270 (1995). 
es la fuente de legitimidad primera de aquellos; por otro lado, la Constitución será formal y materialmente superior al derecho de la integración cuando también lo disponga la propia Constitución, lo que es la esencia misma del concepto norma de normas.

La fallida Constitución europea nos ofreció, como buena parte de los avances en la integración europea, valiosas decisiones de tribunales constitucionales cuyo propósito era salvar la tensión entre ordenamientos internos y normas comunitarias de integración. En este sentido, es de particular interés la Decisión del 1/2004, de 13 de diciembre, del Tribunal Constitucional español, que exactamente se preguntaba en su primera cuestión sobre "la existencia o inexistencia de una contradicción entre la Constitución Española y el artículo I-6 del Tratado por el que se establece una Constitución para Europa". El citado artículo I-6, que resumía las decisiones sobre la primacía del derecho de la Unión Europea del Tribunal de Justicia de las Comunidades Europeas, determinaba que "La Constitución y el derecho adoptado por las instituciones de la Unión en el ejercicio de las competencias que se le atribuyen a esta primarán sobre el derecho de los Estados miembros".

Como base de su decisión, el Tribunal Constitucional reconocía que la cláusula de apertura, prevista en el caso español en el artículo 93 de la Constitución, es el "soporte constitucional básico de la integración de otros ordenamientos con el nuestro, a través de la cesión del ejercicio de competencias derivadas de la Constitución, ordenamientos llamados a coexistir con el Ordenamiento interno" (FJ2). Como se produce cesión de competencias, la Constitución deja de ser la norma que da validez al derecho de la integración, sino que lo son sus propias normas básicas: los tratados de integración. Lo que no evita la necesidad de que el derecho de la Unión no contradiga a la norma fundamental: "Producida la integración debe destacarse que la Constitución no es ya el marco de validez de las normas comunitarias, sino el propio Tratado cuya celebración instrumenta la operación soberana de cesión del ejercicio de competencias derivadas de aquélla, si bien la Constitución exige que el Ordenamiento aceptado como consecuencia de la cesión sea compatible con sus principios $y$ valores básicos" (FJ2). Pero la primacía del derecho de la Unión proclamada en el artículo I-6 no contradice la supremacía de la Constitución porque 
Primacía y supremacía son categorías que se desenvuelven en órdenes diferenciados. Aquélla, en el de la aplicación de normas válidas; esta, en el de los procedimientos de normación. La supremacía se sustenta en el carácter jerárquico superior de una norma y, por ello, es fuente de validez de las que le están infraordenadas, con la consecuencia, pues, de la invalidez de estas si contravienen lo dispuesto imperativamente en aquélla. La primacía, en cambio, no se sustenta necesariamente en la jerarquía, sino en la distinción entre ámbitos de aplicación de diferentes normas, en principio válidas, de las cuales, sin embargo, una o unas de ellas tienen capacidad de desplazar a otras en virtud de su aplicación preferente o prevalente debida a diferentes razones. Toda supremacía implica, en principio, primacía [...] salvo que la misma norma suprema haya previsto, en algún ámbito, su propio desplazamiento o inaplicación. (FJ3)

La separación de ambas funciones, la normadora y la validadora, es diáfana en la redacción del Tribunal Constitucional. La decisión, aunque ha sido criticada desde un punto de vista europeísta más que democrático (v. gr., Díez-Picazo ${ }^{8} 2005,5$ ), quiso evitar la deconstitucionalización material de los ámbitos de determinación del derecho y sus garantías por parte de la Constitución, en cuya línea se había situado la jurisprudencia de la Corte de Luxemburgo, pero mantener la posibilidad de crear un ordenamiento jurídico supranacional. Como afirma Sáiz ${ }^{9}$ recordándonos sentencias como el caso Frontini (Corte italiana, n. 183 de 1973) o la alemana Maastricht (12 de octubre de 1993),

Comportándose como lo ha hecho, el alto Tribunal se ha aproximado a la Corte Constitucional italiana y al Tribunal Constitucional federal alemán, que hace y a muchos años enunciaron, en contextos y circunstancias distintas, pero con una clara identidad de objetivo, la conocida como doctrina de los controlimiti. La integración, se dice, no puede contrariar los principios fundamentales del ordenamiento constitucional ni vulnerar los derechos inalienables de la persona humana; el respeto del contenido esencial de los derechos fundamentales, se sostiene, ha de asegurarse, llegado el caso, frente a la (entonces) Comunidad. Se trataba de definir límites a la primacía del derecho europeo, concebida desde siempre como absoluta por el Tribunal de Justicia. Unos límites que con

8 Luis María Díez-Picazo, Constitución española y Constitución europea, Institut Universitari d'Estudis Europeus, Barcelona, 5 (2005).

9 Alejandro Sáiz Arnáiz, De primacía, supremacía y derechos fundamentales en la Europa integrada: La Declaración del Tribunal Constitucional de 13 de diciembre de 2004 y el Tratado por el que se establece una Constitución, en AA.VV, Constitución española y Constitución europea: análisis de la Declaración del Tribunal Constitucional (DTC 1/2004, de 13 de diciembre), Centro de Estudios Políticos y Constitucionales: Madrid, 2-16 (2005). 
el paso del tiempo se han incorporado a algunos textos constitucionales como, por ejemplo, el alemán, el sueco o el portugués.

\section{PRIMACÍA Y SUPREMACía EN EL NUEVO CONSTITUCIONALISMO LATINOAMERICANO: LOS CASOS DE COLOMBIA (1991), VENEZUELA (1999), ECUADOR (2008) Y BOLIVIA (2009)}

Cabe, por último, entender si las nuevas Constituciones latinoamericanas recogen, y de qué forma, la distinción entre primacía y aplicación que solucionaría jurídicamente, negándola, una posible deconstitucionalización material de los derechos por la vía de los tratados de integración. Debe realizarse el análisis teniendo en cuenta que todas las nuevas Constituciones latinoamericanas apuestan desde los fundamentos axiológicos por una forma de integración, la latinoamericana y caribeña ${ }^{10}$, por lo que es necesario encajar la voluntad constituyente a favor de la integración con la misma voluntad indicadora y garantizadora de los derechos de configuración constitucional.

La primera de las Constituciones del nuevo constitucionalismo latinoamericano, la colombiana de 1991, no plantea dudas respecto a la jerarquía normativa de la Constitución. El artículo 4 de la Constitución colombiana determina que "La Constitución es norma de normas. En todo caso de incompatibilidad entre la Constitución y la ley u otra norma jurídica, se aplicarán las disposiciones constitucionales", por lo que no prevé excepción alguna al respecto. Situación que, desde luego, no imposibilita la primacía de los derechos humanos, recogida explícitamente en el artículo 5. Aunque no se produce una referencia expresa a los tratados internacionales, lo cierto es que se desprende del tenor de dicho artículo "El Estado reconoce, sin discriminación alguna, la primacía de los derechos inalienables de la persona $[. .$.$] " cabe extraer la conclusión de que abarca al derecho$ internacional de los derechos humanos. El artículo 93, por su parte, establece que "Los tratados y convenios internacionales ratificados

10 Cfr. Rubén Martínez Dalmau, La integración en el nuevo constitucionalismo latinoamericano, en Eric Tremolada Álvarez, ed., Crisis y perspectiva comparada de los procesos de integración, 92-96, Universidad Externado de Colombia, Bogotá (2008). 
por el Congreso, que reconocen los derechos humanos y que prohíben su limitación en los estados de excepción, prevalecen en el orden interno. Los derechos y deberes consagrados en esta Carta, se interpretarán de conformidad con los tratados internacionales sobre derechos humanos ratificados por Colombia"; es decir, por un lado otorga aplicación preferente a determinados tratados internacionales sobre el "orden interno" - esto es, sobre la propia Constitución —, y por otro lado menciona específicamente a los tratados internacionales de derechos humanos como parámetro de interpretación constitucional. Cualquier intento de aproximación de este mandato con el artículo 4 de la Constitución colombiana pasa, sin duda, por la distinción entre supremacía jerárquica (de la Constitución) y primacía en la aplicación (de determinados tratados internacionales). La Constitución colombiana, por lo tanto, siguió la órbita iniciada tímidamente por otras constituciones latinoamericanas, como la guatemalteca de 1985 o la peruana de 1979, encaminando - en términos de Fix-Zamudio" — " al reconocimiento de la primacía del derecho convencional internacional, de manera especial en el campo de los derechos fundamentales".

Esta aparente contradicción entre el artículo 4 (supremacía constitucional) y el artículo 93 de la Constitución colombiana, como es sabido y se ha hecho referencia, fue solucionada por la Corte Constitucional colombiana a través de la adaptación del concepto bloque de constitucionalidad. Afirma el fundamento jurídico 12 de la Sentencia C-225/95:

El bloque de constitucionalidad está compuesto por aquellas normas y principios que, sin aparecer formalmente en el articulado del texto constitucional, son utilizados como parámetros del control de constitucionalidad de las leyes, por cuanto han sido normativamente integrados a la Constitución, por diversas vías y por mandato de la propia Constitución. Son pues verdaderos principios y reglas de valor constitucional, esto es, son normas situadas en el nivel constitucional, a pesar de que puedan a veces contener mecanismos de reforma diversos al de las normas del articulado constitucional stricto sensu.

Con independencia de la buena acogida del concepto adaptado, lo cierto es que la solución soslaya el problema, que no es otro que el hecho de que la Constitución sigue siendo, a pesar de cualquier

11 Óp. cit., 149. 
consideración que pueda realizarse al respecto, norma de normas; de lo contrario, no podría ser Constitución. El hecho de que una reforma por parte del constituyente democrático del artículo 93 podría modificar drásticamente la prevalencia de los derechos fundamentales no viene sino a confirmar que la legitimidad de esta prevalencia se encuentra en la misma Constitución; por lo tanto, no es un problema de jerarquía sino de aplicación. En ese sentido, cabe insistir en lo que la decisión de la Corte afirma en segundo plano: que si los derechos de los tratados previstos en el artículo 93 cuentan, en palabras de los magistrados, de "valor constitucional", es "por mandato de la propia Constitución".

El caso del derecho comunitario es similar en varios aspectos. Nada impide que el derecho comunitario se aplique con primacía sobre el ordenamiento interno: de hecho, la Constitución incluye a la integración latinoamericana como un valor dentro del Preámbulo, y se refiere a ella en particular en el artículo 227, en el marco de la generalidad sobre la integración como obligación de promoción pública: "El Estado promoverá la integración económica, social y política con las demás naciones y especialmente, con los países de América Latina y del Caribe mediante la celebración de tratados que sobre bases de equidad, igualdad y reciprocidad, creen organismos supranacionales, inclusive para conformar una comunidad latinoamericana de naciones". El artículo 150.16 confiere al Congreso una general potestad de aprobar o improbar tratados celebrados por el Gobierno, a través de una cláusula de apertura: "Por medio de dichos tratados podrá el Estado, sobre bases de equidad, reciprocidad y conveniencia nacional, transferir parcialmente determinadas atribuciones a organismos internacionales, que tengan por objeto promover o consolidar la integración económica con otros Estados", por lo que la asignación de competencias comunitarias, como se ha referido, requiere de la aplicación preferente del derecho comunitario en el orden interno. Cabe deducir que los tratados internacionales de integración gozan de primacía en el ordenamiento interno pero exclusivamente en el marco de las competencias asignadas, mientras que determinados tratados de derechos humanos gozan de primacía en los casos explícitamente previstos en la Constitución, y que siempre deben suponer una mejora en los derechos respecto a la 
situación anterior. Tanto en un caso como en otro, la Constitución es la norma jerárquica superior: "norma de normas".

Ahora bien, el énfasis de la Constitución Política de Colombia en materia de integración ¿se podría interpretar como una calificación especial a los tratados constitutivos de estos procesos? ¿Estaría dando un tratamiento análogo al que se observa en materia de tratados de derechos humanos? El caso explícito del artículo 227 de la Constitución promoviendo tratados de integración, ilos dotaría de primacía no solo en virtud de las competencias asignadas? Cabe preguntarse hasta qué punto el poder constituyente de 1991 blindó y calificó los tratados de integración de conformidad con el artículo 227 de la Constitución, previendo tratados constitutivos de organismos supranacionales que ejercerán competencias que antes correspondían a instituciones internas, y que serán ahora ejercidas por órganos comunitarios.

Se debe interpretar el artículo 227 como parte del Capítulo 8 titulado De las Relaciones Internacionales que a su vez está integrado en el Titulo VII De la Rama Ejecutiva. La Constitución está específicamente privilegiando a los tratados que crean organismos supranacionales, siempre que su objeto sea la integración económica, social y política con países de América Latina y el Caribe. Es decir, no solo se orienta la política exterior del ejecutivo hacia una región en particular, sino que se pone énfasis en que esa política debe tender hacia la integración. Orientación que además se señala expresamente en el segundo parágrafo del artículo 9, que hace parte del Título I De los Principios Fundamentales: "[...] la política exterior de Colombia se orientará hacia la integración latinoamericana y del Caribe".

El principio de coherencia que debe regir a la actividad interior y exterior del Estado, sumado a las previsiones constitucionales, como precisa Tremolada ${ }^{12}$, es el que nos permitiría hablar de normas convencionales calificadas por fuera del ámbito de los derechos humanos; de lo contrario permitiría que cualquier tratado internacional, por ejemplo los que pactan zonas de libre comercio y que no pretenda la integración Latinoamericana o del Caribe y

12 Eric Tremolada Álvarez, Los organismos supranacionales en la Constitución colombiana: ¿una garantía para el derecho andino, en Eric Tremolada Álvarez, ed., Crisis y perspectiva comparada de los procesos de integración, 103-107, Universidad Externado de Colombia, Bogotá (2008). 
que no constituyan organismos supranacionales, entorpezcan este mandato constitucional que privilegia en particular la integración parcial y sectorial de territorios y de poblaciones.

El control automático de constitucionalidad que debe efectuar la Corte Constitucional de la ley que incorpora los Tratados o Acuerdos de Libre Comercio deberían ser oportunidades para que se determine el alcance del artículo 227 de la Constitución, que a nuestro juicio está hablando de tratados calificados, que en forma sistémica, con las previsiones del Preámbulo y del artículo 9, privilegian organismos supranacionales de integración con América Latina y el Caribe. En otras palabras, que los tratados internacionales de integración gozan de primacía en el ordenamiento interno exclusivamente en el marco de las competencias asignadas, salvo en los casos explícitos del artículo 227 como sucede con determinados tratados de derechos humanos. En todo caso, esta pretendida analogía, que intenta rescatar la vocación latinoamericanista de nuestra Constitución vía parámetros del control de constitucionalidad de tratados no explícitos, no desvirtúa nuestra primera conclusión de que los tratados de integración gozan de primacía en el marco de las competencias cedidas.

Esta conclusión conlleva a un efecto decisivo en el hipotético caso de que un tratado de integración, de cualquier naturaleza, atentara contra un derecho constitucional: puesto que la Constitución refuerza el valor de los derechos humanos, por un lado, y establece la primacía del derecho comunitario solo respecto a las competencias cedidas, cualquier determinación jurídica comunitaria que atentara contra los derechos configurados constitucionalmente sería inconstitucional y no podría ser de aplicación en el país. Se trata de un sistema, como afirma Pinho ${ }^{13}$, mixto entre el monismo y el dualismo, porque determina diferente aplicación, directa o no, de los tratados internacionales de acuerdo con su materia.

El caso venezolano de 1999 cuenta con una peculiaridad: la Constitución confunde textualmente aplicación con jerarquía. El constituyente venezolano no supo ver la diferencia entre los dos conceptos, jerarquía y aplicación, y de hecho los utiliza sin distin-

13 María Fátima Pinho de Oliveira, Los tratados internacionales y sus posibles conflictos en el orden interno a la luz de la Constitución de la República Bolivariana de Venezuela, 7, CONHISREMI, Revista Universitaria de Investigación y Diálogo Académico, No. 3, 127-139, 137-138 (2011). 
ción. El caso más patente es el del artículo 23, cuando determina que "Los tratados, pactos y convenciones relativos a derechos humanos, suscritos y ratificados por Venezuela, tienen jerarquía constitucional y prevalecen en el orden interno, en la medida en que contengan normas sobre su goce y ejercicio más favorables a las establecidas en esta Constitución y en las leyes de la República, y son de aplicación inmediata y directa por los tribunales y demás órganos del Poder Público". Con "jerarquía constitucional" el constituyente venezolano parece referirse al bloque de constitucionalidad, expresión esta última que no aparece en el texto ${ }^{14}$.

La confusión, no obstante, es menos grave de lo que pudiera parecer. Por una parte, el artículo 7 de la Constitución Bolivariana de Venezuela no crea sombras sobre la supremacía constitucional: " $\mathrm{La}$ Constitución es la norma suprema y el fundamento del ordenamiento jurídico. Todas las personas y los órganos que ejercen el Poder Público están sujetos a esta Constitución”. Por otro lado, cabe recordar que la previsión sobre la "jerarquía constitucional" de los tratados de derechos humanos citados en el artículo 23 encuentra su razón de ser en el propio artículo 23, esto es, en la Constitución. No cabe duda de que una modificación constitucional del artículo 23 que sustituyera esta decisión por otra en sentido contrario eliminaría el la "jerarquía constitucional" de los tratados internacionales de derechos humanos; por lo que, desde el punto de vista de la legitimidad, está claro que también en el caso venezolano la Constitución es "norma de normas" y, por lo tanto, goza de supremacía frente a todos los demás instrumentos jurídicos, incluidos los tratados internacionales ${ }^{15}$. Lo que en verdad quiere decir el artículo 23, porque no puede ser de otra manera, es que los tratados internacionales de derechos humanos que prevean normas más favorables para los ciudadanos se aplicarán con preferencia a la Constitución: es el contenido del concepto "jerarquía constitucional" al que se refiere la Constitución de 1999.

14 Cfr. Carlos Ayala Corao, La jerarquía constitucional de los tratados relativos a derechos humanos y sus consecuencias, en Ricardo Méndez Silva, coord., Derecho internacional de los derechos humanos. Memoria del VII Congreso Iberoamericano de derecho Constitucional, 53-54, unAm, México (2002).

15 Esta opinión no es pacífica, puesto que un sector de la doctrina no incide en la diferencia entre jerarquía y aplicación. Cfr., v. gr., Ayala Corao, óp. cit., 50 y ss. 
Por otro lado, el problema no se extiende, afortunadamente, a la relación entre derechos humanos e integración, porque en este caso la Constitución venezolana es clara. Por un lado, la integración latinoamericana es también un valor constitucional citado ampliamente en todo el texto desde el Preámbulo. De hecho, la Constitución solo prevé la promoción de la integración latinoamericana y caribeña, y no incluye otra previsión:

La República promoverá y favorecerá la integración latinoamericana y caribeña, en aras de avanzar hacia la creación de una comunidad de naciones, defendiendo los intereses económicos, sociales, culturales, políticos y ambientales de la región. La República podrá suscribir tratados internacionales que conjuguen y coordinen esfuerzos para promover el desarrollo común de nuestras naciones, y que garanticen el bienestar de los pueblos y la seguridad colectiva de sus habitantes. Para estos fines, la República podrá atribuir a organizaciones supranacionales, mediante tratados, el ejercicio de las competencias necesarias para llevar a cabo estos procesos de integración. Dentro de las políticas de integración y unión con Latinoamérica y el Caribe, la República privilegiará relaciones con Iberoamérica, procurando sea una política común de toda nuestra América Latina.

Pero en lo que nos concierne particularmente, la Constitución no utiliza el término jerarquía, sino el correcto: aplicación preferente. El final del citado artículo 153 así lo incorpora: "Las normas que se adopten en el marco de los acuerdos de integración serán consideradas parte integrante del ordenamiento legal vigente y de aplicación directa y preferente a la legislación interna". Queda claro que la aplicación "directa y preferente" es respecto a la legislación interna, no la constitucional. Por lo que, como en el caso colombiano, tampoco se podría dar hipotéticamente una disminución de los derechos a través de un tratado de integración, por cuanto la determinación competencial está subordinada a determinados valores que, en todo caso, suponen una mejoría en la situación de los derechos.

La Constitución ecuatoriana de 2008 diferencia también con claridad entre jerarquía y aplicación, y establece que la Constitución es la norma jerárquicamente superior, seguida de los tratados internacionales. El artículo 424 señala que "La Constitución es la norma suprema y prevalece sobre cualquier otra del ordenamiento jurídico. Las normas y los actos del poder público deberán mantener conformidad con las disposiciones constitucionales; en caso contrario 
carecerán de eficacia jurídica”, y viene completado por el artículo 425, que establece el sentido de la prelación: "El orden jerárquico de aplicación de las normas será el siguiente: La Constitución; los tratados y convenios internacionales [...]". La aplicación preferente de ciertos tratados internacionales de derechos humanos se establece en el segundo párrafo del artículo 424, cuando determina que " $L a$ Constitución y los tratados internacionales de derechos humanos ratificados por el Estado que reconozcan derechos más favorables a los contenidos en la Constitución, prevalecerán sobre cualquier otra norma jurídica o acto del poder público". No tendría sentido entender que la mención explícita a la Constitución que realiza este segundo párrafo del artículo 424 excluye la aplicación preferente de los tratados internacionales de derechos humanos que establezcan derechos más favorables para los ciudadanos, porque se refiere a derechos "más favorables a los contenidos en la Constitución". Por lo tanto, se aplican con preferencia a esta, supuesto fortalecido por los parámetros de interpretación determinados en el artículo 427: "En caso de duda, [las normas constitucionales] se interpretarán en el sentido que más favorezca a la plena vigencia de los derechos y que mejor respete la voluntad del constituyente [...]", y con la aplicación directa prevista en el artículo $428^{16}$, así como la mención a la "cláusula abierta" que establece expresamente el artículo $417^{17}$.

Respecto al derecho comunitario, cabe destacar que también en el caso ecuatoriano, como en el resto de Constituciones examinadas, la integración latinoamericana es un mandato del constituyente presente desde el Preámbulo, y extendida ampliamente por el texto constitucional. El artículo 276.5 de la Constitución establece que la promoción de la integración latinoamericana es un objetivo del régimen de desarrollo, y el principio integrador está presente en los fundamentos de las relaciones internacionales del Ecuador (artículo 416.1 y 416.11). El artículo 423 determina los fundamentos constitucionales de la integración (en especial con los países

16 "Cuando una jueza o juez, de oficio o a petición de parte, considere que una norma jurídica es contraria a la Constitución o a los instrumentos internacionales de derechos humanos que establezcan derechos más favorables que los reconocidos en la Constitución, suspenderá la tramitación de la causa [...]".

17 "Los tratados internacionales ratificados por el Ecuador se sujetarán a lo establecido en la Constitución. En el caso de los tratados y otros instrumentos internacionales de derechos humanos se aplicarán los principios pro ser humano, de no restricción de derechos, de aplicabilidad directa y de cláusula abierta establecidos en la Constitución". 
de Latinoamérica y el Caribe), y en su numeral 7 especifica que corresponde al Estado ecuatoriano "Favorecer la consolidación de organizaciones de carácter supranacional conformadas por Estados de América Latina y del Caribe, así como la suscripción de tratados $y$ otros instrumentos internacionales de integración regional". Cabe interpretar este artículo de acuerdo con la capacidad que el artículo 419.7 de la Constitución ecuatoriana otorga a la Asamblea Nacional para ratificar o denunciar tratados internacionales que "atribuyan competencias propias del orden jurídico interno a un organismo internacional o supranacional". Como en el caso colombiano, también aquí se necesita hacer valer la primacía del derecho de la integración para atribuir competencias, pues en otro caso quedaría imposibilitada en la realidad dicha atribución. La Constitución, respecto al derecho a la integración, no solo es jerárquicamente superior, sino que también los limita competencialmente. Se concluye, por lo tanto, que cualquier norma hipotética prevista en un tratado de integración que fuera materialmente inconstitucional debería ser declarada como tal y, por lo tanto, no se aplicaría en el ámbito interno ecuatoriano.

En el caso boliviano de 2009, la diferenciación entre jerarquía y aplicación está perfectamente delimitada en el texto constitucional, sin que quepa duda alguna sobre la supremacía constitucional, la cual convive sin pasiones, pero tampoco contradicciones, con la primacía del derecho comunitario e incluso la aplicación preferente de los tratados internacionales de derechos humanos cuando prevean supuestos que favorezcan en mayor medida a las personas.

Empecemos por el último de los casos: los tratados específicos que sean más beneficiosos para los ciudadanos. La Constitución boliviana prevé en el artículo 13.IV que "Los tratados y convenios internacionales ratificados por la Asamblea Legislativa Plurinacional, que reconocen los derechos humanos y que prohíben su limitación en los Estados de Excepción prevalecen en el orden interno. Los derechos y deberes consagrados en esta Constitución se interpretarán de conformidad con los Tratados internacionales de derechos humanos ratificados por Bolivia". Se trata, como puede verse, de la otorgación de la máxima eficacia a los tratados internacionales que prohíben 
limitaciones de derechos durante los estados excepcionales ${ }^{18}$, al tiempo que determina la función de los tratados internacionales de derechos humanos, en general, como parámetros de interpretación. Por su parte, el artículo 256 de la Constitución, siguiendo la tendencia que se ha analizado, nos plantea un supuesto más extenso: "Los tratados e instrumentos internacionales en materia de derechos humanos que hayan sido firmados, ratificados o a los que se hubiera adherido el Estado, que declaren derechos más favorables a los contenidos en la Constitución, se aplicarán de manera preferente sobre esta". Cabe destacar la utilización concreta del verbo "aplicar", que elude conscientemente cualquier referencia a la jerarquía: puesto que es la Constitución la que determina esta aplicación, es la propia Constitución la fuente de legitimidad del efecto primario $\mathrm{y}$, por lo tanto, la norma jerárquicamente superior ${ }^{19}$, tal y como establece el artículo 410, cuando determina los criterios de jerarquía: "[...] La aplicación de las normas jurídicas se regirá por la siguiente jerarquía [...]: 1. Constitución Politica del Estado. 2. Los tratados internacionales [...]".

La incorporación del conocido como "bloque de constitucionalidad" en el artículo 410.II de la Constitución boliviana podría haber empañado la claridad con que la redacción anterior distingue entre aplicación y jerarquía. Con independencia de que el texto apareció durante la negociación en Cochabamba sobre la redacción original de la Asamblea Constituyente, que en ningún momento mencionó al "bloque de constitucionalidad", lo cierto es que el artículo finalmente redactado determina que "La Constitución es la norma suprema del ordenamiento jurídico boliviano y goza de primacía frente a cualquier otra disposición normativa. El bloque de constitucionalidad está integrado por los Tratados y Convenios internacionales en materia de derechos Humanos y las normas de derecho Comunitario, ratificados por el país". Cabría entender que, por la propia denominación, bien conocida, de "bloque de constitucionalidad", así como por su ubicación constitucional, se pondría en entredicho la Constitución cierta; esto es, la característica distintiva

18 Previstos en los artículos 137-140 de la Constitución boliviana de 2009.

19 El segundo apartado del artículo 256, por su parte, insiste en el uso de los tratados internacionales como criterio interpretativo: "Los derechos reconocidos en la Constitución serán interpretados de acuerdo a los tratados internacionales de derechos humanos cuando estos prevean normas más favorables". 
del texto constitucional respecto a otras normas, como los tratados internacionales en materia de derechos humanos y las normas de derecho comunitario.

Pero tanto desde el punto de vista de la legitimidad como de la interpretación, no es válida esta interpretación: por un lado, la Constitución es la única norma que expresa la voluntad del poder constituyente boliviano, por lo que es la única legítima para ordenar al resto del ordenamiento jurídico. Tampoco puede llegarse a aquella conclusión desde la interpretación del texto constitucional, puesto que la frase que encabeza este artículo es rotunda: "La Constitución es la norma suprema del ordenamiento jurídico boliviano y goza de primacía frente a cualquier otra disposición normativa"20; así como lo es la prelación jerárquica que incorpora el propio artículo 410.II, y a la que ya se ha hecho referencia. La Constitución es la fuente primaria de la que nacen las demás normas, y el bloque de constitucionalidad está sometido a esta función constitucional ${ }^{21}$. Los parámetros de interpretación que la propia Constitución establece como prioritarios, esto es, la voluntad del constituyente y el tenor literal del texto (artículo 196.II), eliminan cualquier duda sobre la distinción constitucional entre jerarquía y aplicación ${ }^{22}$.

20 Si bien cabe entender el término "primacía" usado por la Constitución boliviana como "supremacía" en el sentido expuesto en el presente trabajo, por cuanto no excluye la aplicación preferente de los tratados internacionales sobre la propia Constitución en los supuestos establecidos en ella.

21 Cfr. William Josué Ayala Baldelomar, Análisis de la Quinta Parte de la nueva Constitución Política del estado: primacía y reforma de la Constitución, en AA.VV. Miradas: la nueva Constitución boliviana, 217, UMSA - Vicepresidencia de la República, La Paz (2010).

22 Para un sector de la doctrina, no se trata de una decisión coherente de la Constitución boliviana, sino de una "contradicción e incongruencia". Cfr. Carlos Alarcón Mondonio, Análisis y comentario de la Quinta parte de la Constitución. Jerarquía normativa y reforma de la Constitución, en AA.VV. Miradas: la nueva Constitución boliviana, 228 y ss., UMSA - Vicepresidencia de la República, La Paz (2010). 


\section{CONCLUSIONES}

En el marco de una Constitución democrática, el derecho de la integración no podría menoscabar los derechos constitucionales, por cuanto estos gozan de su posición jerárquica de acuerdo con los límites y condiciones que recoge la propia Constitución. La legitimidad de la Constitución democrática como norma suprema del ordenamiento jurídico la dota del mayor rango jerárquico en dicho ordenamiento (supremacía). Por lo tanto, cualquier aplicación de un tratado internacional (en este caso, de integración) que menoscabe un derecho constitucional es materialmente inconstitucional.

El ordenamiento jurídico internacional puede, en todo caso, mejorar la situación de los derechos constitucionales, por cuanto se aplican con preferencia a esta en virtud de las cláusulas de integración generales y las particulares (derechos humanos). El derecho de la integración goza de primacía frente al derecho interno siempre y cuando la Constitución así lo determine a través de las cláusulas de apertura (supremacía constitucional), y de forma limitada por la cesión expresa de las competencias que pueden gobernarse desde instancias supranacionales. La norma constitucional puede ser, asimismo, derrotable, si el tratado internacional se aplica sobre ella porque la propia Constitución incorpora una previsión en este aspecto (cláusulas particulares sobre la aplicación preferente de los tratados internacionales de derechos humanos que sean más beneficiosos para las personas).

Las nuevas Constituciones latinoamericanas materializan en general esta diferencia entre primacía y supremacía y dejan clara la supremacía constitucional frente a la primacía del derecho de la integración, aun cuando en algunos casos (Venezuela, 1999) se alude al rango jerárquico. 


\section{REFERENCIAS}

\section{Libros}

Araceli Mangas Martín \& Diego Liñán Nogueras, Instituciones y derecho de la Unión Europea, Tecnos, Madrid (2006).

Guy Isaac, Manual de derecho comunitario general, Ariel, Barcelona (2000).

Luis María Díez-Picazo, Constitución española y Constitución europea, Institut Universitari d'Estudis Europeus Barcelona (2005).

\section{Colaboraciones en publicaciones colectivas}

Alejandro Sáiz Arnáiz, De primacía, supremacía y derechos fundamentales en la Europa integrada: La Declaración del Tribunal Constitucional de 13 de diciembre de 2004 y el Tratado por el que se establece una Constitución, en AA.VV, Constitución española y Constitución europea: análisis de la Declaración del Tribunal Constitucional (DTC 1/2004, de 13 de diciembre), Centro de Estudios Políticos y Constitucionales: Madrid, 2-16 (2005).

Carlos Alarcón Mondonio, Análisis y comentario de la Quinta parte de la Constitución. Jerarquía normativa y reforma de la Constitución, en AA.VV. Miradas: la nueva Constitución boliviana, 228 y ss., UMSA - Vicepresidencia de la República, La Paz (2010).

Carlos Ayala Corao, La jerarquía constitucional de los tratados relativos a derechos humanos y sus consecuencias, en Ricardo Méndez Silva, coord., Derecho internacional de los derechos humanos. Memoria del VII Congreso Iberoamericano de derecho Constitucional, 53-54, unam, México (2002).

Eric Tremolada Álvarez, Los organismos supranacionales en la Constitución colombiana: ¿una garantía para el derecho andino, en Eric Tremolada Álvarez, ed., Crisis y perspectiva comparada de los procesos de integración, 103-107, Universidad Externado de Colombia, Bogotá (2008).

Rubén Martínez Dalmau, La integración en el nuevo constitucionalismo latinoamericano, en Eric Tremolada Álvarez, ed., Crisis y perspectiva comparada de los procesos de integración, 92-96, Universidad Externado de Colombia, Bogotá (2008).

William Josué Ayala Baldelomar, Análisis de la Quinta Parte de la nueva Constitución Política del estado: primacía y reforma de la Constitución, en AA.VV. Miradas: la nueva Constitución boliviana, 217, UMSA - Vicepresidencia de la República, La Paz (2010). 


\section{Publicaciones seriadas}

Héctor Fix-Zamudio, El derecho internacional de los derechos humanos en las Constituciones latinoamericanas y en la Corte Interamericana de derechos Humanos, Revista Latinoamericana de derecho, No. 1, 141-180 (2004).

Humberto Nogueira Alcalá, Los derechos esenciales o humanos contenidos en los tratados internacionales y su ubicación en el ordenamiento jurídico nacional: doctrina y jurisprudencia, 9 Ius et Praxis, No. 1, 403-466 (2003).

María Fátima Pinho de Oliveira, Los tratados internacionales y sus posibles conflictos en el orden interno a la luz de la Constitución de la República Bolivariana de Venezuela, 7, ConHISREMI, Revista Universitaria de Investigación y Diálogo Académico, No. 3, 127-139 (2011).

Miguel Ángel Alegre Martínez, La primacía del derecho comunitario sobre el ordenamiento jurídico estatal: aspectos constitucionales, Revista de derecho Político No. 38, 43-174 (1993).

Miriam Lorena Henríquez Viñas, Jerarquía de los tratados de derechos humanos: análisis jurisprudencial desde el método de casos, 6 Estudios constitucionales No. 2, 73119 (2008).

Riccardo Guastini, Normas supremas, Doxa. Cuadernos de Filosofía del derecho, No. 17-18, 257-270 (1995). 
